\title{
Illuminating Olea europaea L. endophyte fungal community
}

\author{
Daniela Costa $^{\mathrm{a}, 2}$, Telma Fernandes ${ }^{\mathrm{a}, 1,2}$, Fátima Martins ${ }^{\mathrm{b}}$, José A. Pereira ${ }^{\mathrm{b}}$, Rui M. Tavares ${ }^{\mathrm{a}}$, \\ Pedro M. Santos ${ }^{c}$, Paula Baptista ${ }^{\mathrm{b}}$, Teresa Lino-Neto ${ }^{\mathrm{a}, *}$ \\ ${ }^{a}$ BioSystems \& Integrative Sciences Institute (BioISI), Plant Functional Biology Centre, University of Minho, Campus de Gualtar, 4710-057, Braga, Portugal \\ ${ }^{\mathrm{b}}$ Centro de Investigação de Montanha (CIMO), Instituto Politécnico de Bragança, Campus de Santa Apolónia, 5300-253, Bragança, Portugal \\ ${ }^{\mathrm{c}}$ Centre of Molecular and Environmental Biology (CBMA), University of Minho, Campus de Gualtar, 4710-057, Braga, Portugal
}

\section{A R T I C L E I N F O}

\section{Keywords:}

Ecological function

Endophytes

Fungi

Metabarcoding

Olive cultivars

Phyllosphere

\begin{abstract}
A B S T R A C T
A wide array of fungal endophytes is known to inhabit plant tissues and were recently recognized as essential for plant health. A better description of the scarcely known endophyte microbiota in olive tree phyllosphere is the first step for elucidating the microbial interactions that lead to olive disease establishment. In this work, the fungal endophytic community of the phyllosphere of different olive tree cultivars (Cobrançosa, Galega vulgar, Madural, Picual, Verdeal Transmontana) is revealed by using a metabarcoding strategy targeting ITS1 barcode. A total of 460 OTUs were obtained, increasing the broad view of fungal endophytes inhabiting the olive tree phyllosphere, in particular yeast endophytes. New endophytes were persistently found in all cultivar tissues. Different olive tree cultivars depicted distinct endophyte communities. Olive cultivars exhibited dissimilar amounts of fungi with distinct ecological functions, which could explain at least in part their differential susceptibility/tolerance to olive diseases.
\end{abstract}

\section{Introduction}

Healthy plants are commonly colonized by mutualistic or commensal microbes, as well as pathogens. Modifications or imbalances in this functional core microbiota have been described to lead to plant disease (Gomes et al., 2019; Bettenfeld et al., 2020). The specific microbial interactions occurring in the surface (epiphytes) or within (endophytes) plant organs are thus responsible, at least in part, for disease establishment and progression. For example, differences in the physicochemical structure of plant organs from distinct olive cultivars were recently described to affect the resident microbial communities, which could partially explain differential susceptibility of cultivars to disease (Gomes et al., 2019; Fernández-González et al., 2020; Mina et al., 2020a). Playing such an important role for plant health, more information about microbial communities interacting with plants should be available, in particular for those crops that are facing stresses that limit their production, as occurring in olive trees.

Olive (Olea europaea L.) is one of the most important crop within the Mediterranean region, due to its high economic value and health benefits. There are more than 800 million olive trees worldwide, of which more than $90 \%$ are grown for olive oil production and the remaining for table olives (Uylaşer and Yildiz, 2014). Currently, one of the major problems faced by olive producers is the reduction of olive oil production and damages in olive groves caused by pests and diseases (Delrio and Lentini, 2017). Although effective, the use of conventional chemical methods has been recognized as causing serious problems to our health and environment (Pingali and Gerpacio, 1997; Aktar et al., 2009). Also, currently no treatment is available to some olive diseases, such as olive quick decline syndrome caused by Xylella fastidiosa (Cariddi et al., 2014; Cardinale et al., 2018; Giampetruzzi et al., 2020). New environmentally friendly alternatives include the use of endophytes as biological control agents (BCA) for controlling plant pathogens (Backman and Sikora, 2008; Eljounaidi et al., 2016; Raymaekers et al., 2020). The microbial communities that are naturally associated with plants have been recognized for long as a source of promising biocontrol candidates that could be used for improving plant health (Aranda et al., 2011; Gomes et al., 2019; Anguita-Maeso et al., 2020). Such emerging tools have been widely reported (de Silva et al., 2019; de Lamo and Takken, 2020), some of them including olive tree endophytes (e.g. Preto et al., 2017; Nigro et al., 2018; Azabou et al., 2020). To get further insights on plant

\footnotetext{
* Corresponding author.

E-mail address: tlneto@bio.uminho.pt (T. Lino-Neto).

1 Current Address: Instituto de Tecnologia Química e Biológica António Xavier, Universidade Nova de Lisboa (ITQB NOVA), Oeiras 2780-157, Portugal.

2 These authors contributed equally to this work.
} 
interacting microbes and search for putative biocontrol agents, several studies have recently focused on the microbiota associated to olive tree, but most of them have been performed using culture-dependent approaches (de Freitas Sia et al., 2013; Pascazio et al., 2015; Martins et al., 2016; Preto et al., 2017; Gomes et al., 2018; Materatski et al., 2019; Mina et al., 2020b). Far less studies using non-cultured approaches (such as metabarcoding) were performed, but these were mainly concerned to rhizosphere microbiota (Müller et al., 2015; Fernández-González et al., 2019, 2020). As far as we know, few studies have used high-throughput methods for studying olive phyllosphere and carposphere communities. Abdelfattah et al. (2015) reported the fungal diversity from olive leaves, flowers, and fruits, but only used a single olive tree cultivar (cv. Ottobratica) and did not discriminate among endophytic and epiphytic communities. Recently, the bacterial and fungal endophytic communities associated with $X$. fastidiosa-infected and -uninfected olive trees from two different cultivars (Vergine et al., 2020), and from susceptible and resistant olive cultivars to olive quick decline syndrome (Giampetruzzi et al., 2020) were studied using metabarcoding approaches. The results emphasized the importance of getting a broader view of microbial communities from different olive cultivars. In this work, we present the fungal endophytic communities inhabiting the phyllosphere (leaves and twigs) of different olive tree cultivars (Cobrançosa, Galega vulgar, Madural, Picual and Verdeal Transmontana) by using a metabarcoding approach.

With this study, we aim i) to get a deeper insight on microbial diversity of olive tree phyllosphere, ii) to decipher the effect of host genotype (at cultivar level) and plant organs on the assembling of fungal endophyte communities, iii) to suggest a core endophytic microbiota of the phyllosphere of olive cultivars, and iv) to determine the ecological function of endophytes from each cultivar.

\section{Materials and methods}

\subsection{Sampling and DNA extraction}

Olive trees (Olea europaea L.) from the cultivars Cobrançosa, Galega vulgar, Madural, Picual and Verdeal Transmontana, presented in three to five olive orchards in the Iberian Peninsula (Figure S1 and Table S1), were used to collect the plant material. All these orchards encompass olive trees with ages ranging from 30 to 40 years, planted at a density of $7 \times 7 \mathrm{~m}$, and have been managed by following the integrated production guidelines (Malavolta and Perdikis, 2018). Some sampled orchards contained up to three different cultivars (Cobrançosa, Madural and Verdeal Transmontana in Bragança), but others only displayed a single cultivar (Galega vulgar in Castelo Branco, Picual in Spain). Samples of apparently healthy twigs and their adherent leaves were collected from six to seven branches per tree, taking into consideration the four main cardinal directions. Samples were collected in sterile plastic bags, maintained at $4{ }^{\circ} \mathrm{C}$ and processed within two days. The surface sterilization was performed by washing the plant material with deionized water, followed by the sequential immersion in ethanol $70 \%(\mathrm{v} / \mathrm{v})$ for 2 min, bleach (3-5\% chlorine) for $3 \mathrm{~min}$, and ethanol $70 \%(\mathrm{v} / \mathrm{v})$ for 1 $\min$. Following 3 washes in sterile deionized water, the water excess was removed, and plant samples were kept at $-80{ }^{\circ} \mathrm{C}$ until DNA extraction. After homogenizing the plant tissues with liquid nitrogen, the total DNA extraction was performed with ZR Fungal/Bacterial DNA MiniPrep ${ }^{\mathrm{TM}}$ kit (Zymo Research, USA), according to the manufacturer's recommendations.

\subsection{Fungal ITS1 amplification and sequencing}

To assess the extracted DNA integrity, the internal transcribed spacer 1 (ITS1) regions were amplified using the universal primers ITS1-F (CTTGGTCATTTAGAGgAAGTAA, (Mitchell and Zuccaro, 2006) and ITS2 (GCTGCGTTCTTCATCGATGC, (Mitchell and Zuccaro, 2006)). PCR reaction mixture $(25 \mu \mathrm{l})$ contained $1 \mathrm{x}$ reaction buffer, $100 \mu \mathrm{M}$ of each
dNTP (NZYTech, Portugal), $200 \mathrm{nM}$ of each primer, $2 \mathrm{mM} \mathrm{MgCl} 2,0.05 \mathrm{U}$ Taq DNA Polymerase (Frilabo, Portugal) and $1 \mu \mathrm{l}$ of DNA template (30 $\mathrm{ng} / \mu \mathrm{l})$. Amplifications were performed in a MJ Mini BioRad ${ }^{\circledR}$ thermocycler using the following protocol: initial denaturation $4 \mathrm{~min}$ at $94^{\circ} \mathrm{C}$; 35 cycles of $30 \mathrm{~s}$ at $94^{\circ} \mathrm{C}, 30 \mathrm{~s}$ at $52^{\circ} \mathrm{C}$ and $30 \mathrm{~s}$ at $72{ }^{\circ} \mathrm{C}$; final elongation at $72{ }^{\circ} \mathrm{C}$ for $10 \mathrm{~min}$. PCR products were run on a $1 \%(\mathrm{w} / \mathrm{v})$ agarose gel, stained with Green Safe Premium (NZYTech, Portugal). The DNA concentration of those samples that resulted in a successful amplification, were accurately quantified by using a fluorescent DNA quantification assay with $d s D N A B R$ (Broad Range) Assay Kit (ThermoFisher Scientific, USA). DNA-specific fluorescence was then detected with a Qubit 3.0 Fluorometer (ThermoFisher Scientific, USA). Equimolar aliquots of 4-10 replicate tree samples were then combined to get three to five biological replicates (orchards) per organ and studied cultivar (except for cv. Galega vulgar twigs that comprised only two samples). Fungal endophytic communities were assessed by metabarcoding (Illumina MiSeq), through paired-end sequencing $(2 \times 250 \mathrm{bp})$ for the ITS1 region using a sequencing service provider (BaseClear, Netherlands). ITS1F and ITS2 primers with Illumina Nextera adapters, barcode and linker (ITS1F AATGATACGGCGACCGAGATCTACACGGCTTGGTCATTTAGAGGAAGTAA; ITS2 CAAGCAGAAGACGGCATACGAGATTCCCTTGTCTCCCGGCTGCGTTCTTCATCGATGC

(Smith and Peay, 2014)) were used for sequencing with an amplicon size around 320bp. Raw reads for each olive tree twig and leaf sample were deposited in NCBI Sequence Read Archive (http://www.ncbi.nlm.nih. gov/sra) under BioProject number PRJNA588305.

\subsection{Processing of sequencing data}

FASTQ sequence files were generated using the Illumina Casava pipeline version 1.8.3. Initial quality assessment was based on data passing the Illumina Chastity filtering. Reads containing adapters and/or PhiX control signals were removed using an in-house filtering protocol. Read trimming based on quality scores was performed in Sickle (Joshi and Fass, 2011) using the default parameters. Bayeshammer module from SPAdes package (Nurk et al., 2013) was used to correct errors in reads before merging. The merging of overlapping paired-end reads and further quality filtering was performed using Usearch version 8.0.1623 (Edgar, 2010). Filtering based on sequence size was then applied with fastq-mcf from ea-utils package (Aronesty, 2011). The micca version 1.7.0 software pipeline (Albanese et al., 2015) was performed i) to load the datasets into a single FASTQ file, ii) to discard sequences with an expected error rate greater than $1 \%$, iii) to assign similar sequences (threshold $97 \%$ ) to Operational Taxonomic Units (OTUs) and remove chimeric sequences, and iv) to assign taxonomy to each sequence with a reference database for fungi (UNITE database version 8.0, (Nilsson et al., 2018). Sequences of unclassified OTUs were further searched using NCBI-BLAST (Edgar, 2010) to understand their taxonomic classification. OTUs that were not assigned to any taxonomic level (unclassified reads) and with less than 5 sequences were not included in further analysis. Since differences in sampling depth were detected and for mitigating biases, all datasets were subsampled using QIIME 1.9.0 (Caporaso et al., 2010) for an even number of sequences (1659 reads, found in a twigs sample from cv. Verdeal Transmontana; Table S2). Subsampling led to the exclusion of samples from cvs. Galega vulgar, Madural, Picual and Verdeal Transmontana, which resulted in the use of only two samples from certain cultivars.

\subsection{Diversity and similarity analysis}

The endophytic fungal diversity was evaluated by determining the fungal richness (number of OTUs) and abundance (number of sequences per OTU) among cultivars and organs. PAST3 (Hammer et al., 2001) was used for estimating diversity indices [Simpson's Index of Diversity (1-D) and Shannon index $\left.\left(H^{\prime}\right)\right]$, as well as for computing rarefaction curves with individual-based rarefaction. Reads coverage for each sample was determined using Good's coverage estimator (Good, 1953). 1-D 
measures evenness of a community and represents the probability that two individuals randomly selected from a sample will belong to different species (Magurran, 1988; Hughes and Bohannan, 2004), while $H^{\prime}$ measures diversity in a community by taking into account the number of individuals as well as the number of taxa (Hughes and Bohannan, 2004; Hill et al., 2003). Differences in the fungal endophytic composition and diversity among cultivars and organs were compared by a one-way ANOVA, followed by Tukey's multiple comparison test, performed by the analysis tools of GraphPad Prism 7.00 (GraphPad Software, La Jolla, California, USA).

All subsequent analysis was performed using RStudio software and considering the relative abundance of OTUs with more than 5 sequences. To compare the similarity of fungal community between cultivars (Cobrançosa, Galega vulgar, Madural, Picual and Verdeal Transmontana) and organs (twigs and leaves), a non-metric multidimensional scaling (NMDS) was performed using square root transformation of data for all olive tree replicates. NMDS was performed with Bray-Curtis dissimilarity and Jaccard's similarity coefficients using vegdist() of the vegan package (Oksanen et al., 2019) to calculate indices matrix and metaMDS() of the same package to obtain the ordination graph. Kruskal's stress was used as a measure of model's goodness of fit (stress values lower than 0.2 represents a good ordination and higher than 0.3 indicates plots with poor representation; Kruskal and Wish, 1978). Analysis of similarity (ANOSIM) was performed with Bray-Curtis coefficient using Community Package 5.0 (CAP 5.0, Henderson and Seaby, 2014). ANOSIM allows to understand the significance $(p<0.05)$ of similarity/dissimilarity of defined groups. Positive values $(+1)$ indicates that all the most similar samples are within the same group and negative $(-1)$ indicates that the most similar samples are all outside of the groups. The similarity of Percentages (SIMPER) was also performed using CAP 5.0 to understand which OTUs contributed the most to dissimilarities in significantly different groups from ANOSIM. Multivariate statistical tests of significance (PERMANOVA) were performed to understand which factors are more significant in shaping the community structure. PERMANOVA was computed by adonis () function of vegan package (Oksanen et al., 2019), taking into consideration $p<0.05$ as significant (Clarke, 1993). Core endophyte communities were defined by the prevalent OTUs (present in all samples) of each cultivar or organ. Determination of indicator species (or OTUs) of different groups was performed using indval( ) function in the package labdsv of RStudio. The association of OTUs to specific cultivars/organs was measured by IndVal index (from 0 to 1 ), in which IndVal $>0.5$ represents the most constant and specific species (Dufrene and Legendre, 1997).

The functional group of each OTU was assigned using FUNGuild (Nguyen et al., 2016). Corrections using literature search were performed when necessary. Beneficial species include those promoting plant growth or conferring tolerance to stress, while pathogens include described pathogenic or opportunistic species to any plant host. Symbionts include commensal or mutualist species, while saprobe corresponds to species found in dead or decaying organic matter.

\section{Results and discussion}

This study presents the fungal endophytic community in the phyllosphere (twigs and leaves) of different olive tree cultivars (Cobrançosa, Galega vulgar, Madural, Picual, Verdeal Transmontana), using the pairedend Illumina MiSeq platform targeting the ITS1 region. A set of 4,323,154paired-end Illumina MiSeq ITS1 raw reads was generated from 36 orchard samples from five cultivars (Table S2), ranging from 61,513 to 274,045 raw reads per sample. From all high-quality sequences $(2,847,567)$, obtained after exclusion of singletons and chimeric sequences, almost $72 \%$ of total reads were identified as non-fungal OTUs/ unclassified. These reads clustered into 588 OTUs with 280 OTUs comprising more than 5 reads. From those with more than 5 reads, a large number corresponded to plant (81 OTUs, $95 \%$ of total reads) or insect (10 OTUs, $3 \%$ of total reads) OTUs, while the remaining 189 (1.7
$\%$ of total reads) retrieved similarity with unclassified fungal taxa, according to NCBI-BLAST. After subsampling, classified sequences (with an amplicon average of $320 \mathrm{bp)}$ were assigned into 460 fungal OTUs (Table S3). Good's coverage was higher than 0.98 to all samples. In the end, a total of 460 OTUs were included in 3 phyla, 20 classes, 50 orders, 105 families, 137 genera and 54 species with more than $97 \%$ of identity (Tables S3 and S4). The high number of unclassified OTUs (280) and unidentified families (39\% of all assigned OTUs) agrees with the huge olive tree-associated fungal diversity yet to be discovered, as previously suggested for the fungal rhizosphere communities of some olive cultivars (Fernández-González et al., 2019).

\subsection{Discrimination of fungal endophytic communities}

The fungal community diversity among cultivars/organs was compared by computing rarefaction curves and determining the richness $(S)$ and diversity indices [Simpson's (1-D) and Shannon's $\left.\left(H^{\prime}\right)\right]$. Rarefaction curves suggested that samples were well represented and could give information about fungal communities, although some rarefaction curves (mainly from twig communities) did not reach an asymptote, suggesting that more OTUs could have been detected (Figure S2). The comparison among olive tree cultivars revealed that Galega vulgar had the highest richness $(S)$ and diversity (1-D and $\left.H^{\prime}\right)$ in both organs, although only statistically significant for richness when comparing to Cobrançosa, Picual and Verdeal Transmontana (Table 1). Indeed, lowest richness and diversity were observed on both Picual organs, when compared with all other cultivars. Previous studies also reported a higher endophytic richness in cv. Galega vulgar leaves, when compared to cv. Cobrançosa (Materatski et al., 2019), suggesting conditions in the former cultivar for shaping a more diverse fungal endophyte community. The diversity results also revealed that twig communities always presented a higher number of detected taxa $(S)$ in relation to leaf communities, as previously reported when using culture-dependent methods targeting olive tree microbiome (Gomes et al., 2018). In any case, statistically significant differences in diversity indexes (1-D and $H^{\prime}$ ) among twig and leaf communities were not detected $(p>0.05)$, suggesting a relative evenness of their community abundances. Cluster analyses (two-dimensional NMDS) of fungal endophytic communities, based on Bray-Curtis and Jaccard's similarity measures, resulted in a good representation of olive tree endophyte communities (Kruskal stress $\leq 0.2$ ) (Fig. 1). In both, Picual samples (leaves and twigs) clustered together, revealing the factor 'cultivar' as an important aspect for discriminating endophyte communities. Also, 'sampling site' may have an influence on fungal assemblages, as cultivars sampled in the same location (Cobrançosa, Madural and Verdeal Transmontana) were not discriminated. Indeed, olive 'cultivar' factor was able to explain the dissimilarity in fungal community (ANOSIM, $R=0.33, p<0.001$; Table S5), as well as 'organ' (ANOSIM, $R=0.32, p<0.001$ ). Although less significant, 'sampling site' (ANOSIM, $R=0.47, p<0.05$ ) and 'sampling date' (ANOSIM, $R=0.43, p<0.05$ ) also explained the variation among samples. Among cultivars, fungal assembling on cv. Picual was significantly distinctive from all other cultivars [cv. Galega vulgar (ANOSIM, R $=0.89, p<0.01$ ), cv. Verdeal Transmontana (ANOSIM, $\mathrm{R}=0.63, p<$ 0.001 ), cv. Madural (ANOSIM, $\mathrm{R}=0.68, p<0.001$ ) and cv. Cobrançosa (ANOSIM, $\mathrm{R}=0.52, p<0.001$ ). Although less significant, the same pattern was observed for fungal assemblages of cv. Galega vulgar. The fungal endophyte communities present in leaves were quite homogeneous among cultivars (ANOSIM, $R=0.21, p<0.05$ ), even when they were collected from farther sites, displaying different edaphoclimatic conditions (Table S5). On the other hand, twig communities displayed higher dissimilarity (ANOSIM, $R=0.50, p=0.001$ ). Indeed, cv. Picual presented a significantly distinct fungal assembling from cvs. Cobrançosa (ANOSIM, $R=0.74, p<0.01$ ), Madural (ANOSIM, $R=0.89, p<0.05$ ) and cv. Galega vulgar (ANOSIM, $R=0.95, p<0.05$ ) in twigs community. These results suggest the presence of particular factors shaping the endophyte communities in cv. Picual. Being collected from the most 
Table 1

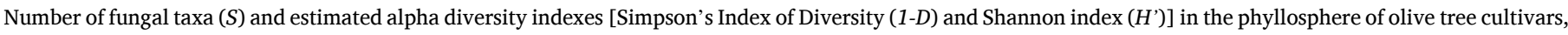

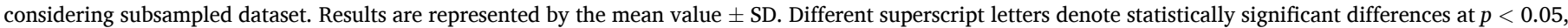

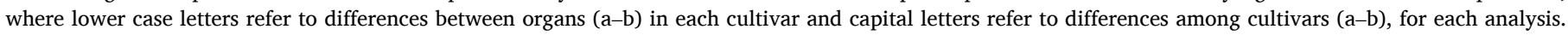
Significant differences are highlighted in bold.

\begin{tabular}{|c|c|c|c|c|c|c|c|c|c|}
\hline \multirow{2}{*}{ Cultivar } & \multicolumn{3}{|l|}{$S$} & \multicolumn{3}{|l|}{$1-D$} & \multicolumn{3}{|l|}{$H^{\prime}$} \\
\hline & Twig & Leaf & TOTAL & Twig & Leaf & TOTAL & Twig & Leaf & TOTAL \\
\hline Cobrançosa & $45.40 \pm 17.8^{\mathrm{aB}}$ & $24.67 \pm 7.0^{\mathrm{aA}}$ & $37.63 \pm 17.6^{B}$ & $0.64 \pm 0.3^{\mathrm{aA}}$ & $0.57 \pm 0.3^{\mathrm{aA}}$ & $0.62 \pm 0.3^{\mathrm{A}}$ & $1.81 \pm 0.8^{\mathrm{aA}}$ & $1.42 \pm 0.8^{\mathrm{aA}}$ & $1.66 \pm 0.7^{\mathrm{A}}$ \\
\hline Galega vulgar & $95.00 \pm 9.9^{\mathrm{aA}}$ & $54.00 \pm 4.2^{\mathrm{aA}}$ & $74.50 \pm 24.5^{\mathrm{A}}$ & $0.85 \pm 0.1^{\mathrm{aA}}$ & $0.84 \pm 0.2^{\mathrm{aA}}$ & $0.84 \pm 0.1^{\mathrm{A}}$ & $2.81 \pm 0.3^{\mathrm{aA}}$ & $2.69 \pm 0.9^{\mathrm{aA}}$ & $2.75 \pm 0.5^{\mathrm{A}}$ \\
\hline Madural & $55.33 \pm 18.0^{\mathrm{aAB}}$ & $50.00 \pm 42.4^{\mathrm{aA}}$ & $53.20 \pm 24.9^{\mathrm{AB}}$ & $0.79 \pm 0.1^{\mathrm{aA}}$ & $0.47 \pm 0.5^{\mathrm{aA}}$ & $0.66 \pm 0.3^{\mathrm{A}}$ & $2.34 \pm 0.3^{\mathrm{aA}}$ & $1.49 \pm 1.6^{\mathrm{aA}}$ & $2.00 \pm 0.9^{\mathrm{A}}$ \\
\hline Picual & $33.00 \pm 6.0^{\mathrm{aB}}$ & $24.50 \pm 0.7^{\mathrm{aA}}$ & $29.71 \pm 7.5^{B}$ & $0.57 \pm 0.3^{\mathrm{aA}}$ & $0.58 \pm 0.1^{\mathrm{aA}}$ & $0.57 \pm 0.2^{\mathrm{A}}$ & $1.48 \pm 0.8^{\mathrm{aA}}$ & $1.30 \pm 0.2^{\mathrm{aA}}$ & $1.43 \pm 0.6^{\mathrm{A}}$ \\
\hline Verdeal Transmontana & $48.00 \pm 18.7^{\mathrm{aB}}$ & $30.50 \pm 3.5^{\mathrm{aA}}$ & $41.00 \pm 16.4^{\mathrm{B}}$ & $0.81 \pm 0.1^{\mathrm{aA}}$ & $0.82 \pm 0.0^{\mathrm{aA}}$ & $0.81 \pm 0.1^{\mathrm{A}}$ & $2.32 \pm 0.4^{\mathrm{aA}}$ & $2.14 \pm 0.1^{\mathrm{aA}}$ & $2.25 \pm 0.3^{\mathrm{A}}$ \\
\hline TOTAL & $49.56 \pm 22.4^{\mathrm{a}}$ & $35.09 \pm 19.6^{\mathrm{a}}$ & - & $0.70 \pm 0.2^{\mathrm{a}}$ & $0.65 \pm 0.3^{\mathrm{a}}$ & - & $2.00 \pm 0.7^{\mathrm{a}}$ & $1.77 \pm 0.9^{\mathrm{a}}$ & - \\
\hline
\end{tabular}
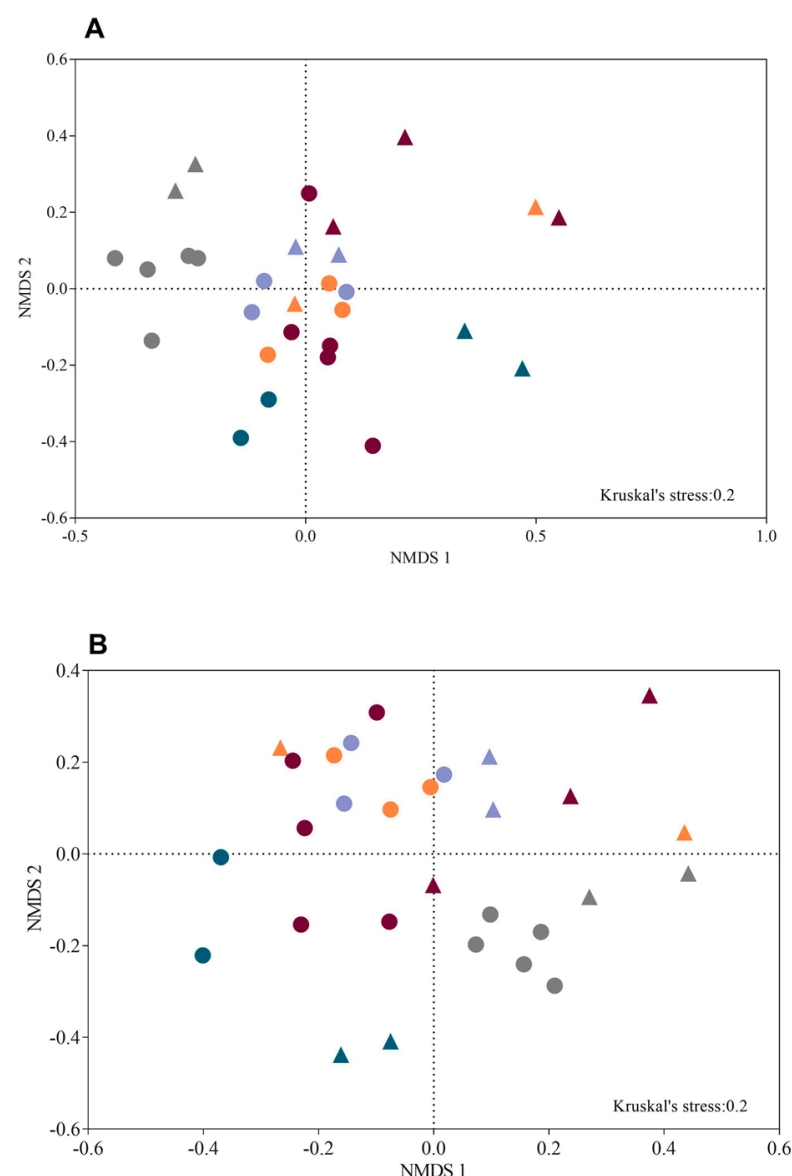

Leaves

- Cobrançosa

- Galega vulgar

$\triangle$ Madural

A Picual

Verdeal

Transmontana

Twigs

Cobrançosa

Galega vulgar

Madural

Picual

Verdeal

Transmontana

Fig. 1. Non-metric multidimensional scale (NMDS) plots for cluster analyses of the fungal endophyte community grouped by olive tree cultivars (Cobrançosa, Galega vulgar, Madural, Picual and Verdeal Transmontana) and their respective organs (Twigs and Leaves) using the Bray-Curtis coefficient (A) and Jaccard's index (B). Fungal communities of different olive tree cultivars/organs are represented by different colors/shapes.

distant sampling site, the microclimate could be an important driving force for structuring the endophytic fungal communities present in cv. Picual, as already reported for the olive tree phyllosphere using culture-dependent methods (Gomes et al., 2018). Indeed, from all the collection sites used in this study, Jaén (the sampling site of cv. Picual) was further apart and presented slightly higher average temperatures (in the year before collection) and lower average precipitation than the sampling sites of cvs. Cobrançosa, Madural and Verdeal Transmontana that share the same edaphoclimatic conditions. Furthermore, the fungal communities inhabiting leaves and twigs were quite heterogeneous mainly considering distinct cultivars (Table S5). Although cultivar and organ were more significant in shaping fungal communities, this also agrees with importance of 'sampling site' factor.

The whole fungal communities differed significantly among cultivars
(PERMANOVA, $R^{2}=0.297, p=0.001$ ), which explained about $30 \%$ of the variation among fungal communities (Table S6). The organ (twigs or leaves) also contributed for fungal distribution (PERMANOVA, $R^{2}=$ $0.095, p=0.001$ ), but explaining only $10 \%$ of community variance. Although less significant, sampling site contributed to $12 \%$ of community variance (PERMANOVA, $R^{2}=0.119, p=0.01$ ). No contribution of sampling date was detected. Many biotic and abiotic factors are currently known to shape the microbiota of phyllosphere, including environmental variables, season, soil management systems, host genotype (cultivar), and geographical location (Copeland et al., 2015; Hardoim et al., 2015; Compant et al., 2019). Regarding olive tree microbiota, Martins et al. (2016) suggested that differences in fungal endophyte community were explained by organ type (root, twig and leaf), sampling site, and season, although they have used a reduced 
number of phyllosphere isolates (44). In a more extensive study (using 125 isolated fungal OTUs), the major drivers shaping the endophytic composition were also found to be the plant organ and climatic factors, such as rainfall and temperature (Gomes et al., 2018). In the present work, where five different cultivars were studied, the factor that contributed the most to fungal variation was 'cultivar' rather than 'plant organ' or 'sampling site'. This result agrees with the assumption that cultivar specific traits, such as chemical composition and physical features, are responsible for shaping the phyllosphere communities, in particular endophyte communities (Mina et al., 2020b). Furthermore, 'cultivar' was also reported to be the main factor to structure the endophyte bacterial and fungal communities residing in belowground tissues of 36 olive cultivars from the World Olive Germplasm Collection, instead of geographical origin (Fernández-González et al., 2019).

\subsection{Composition of fungal endophytic communities among olive cultivars}

Ascomycota and Basidiomycota OTUs were the richest phyla in the whole fungal community (78 \% and $15 \%$, respectively), followed by Mucoromycota phylum $(0.22 \%)$ (Figure S3A). This trend was also observed for the abundance of each phylum (Ascomycota: $92 \%$; Basidiomycota: $4.5 \%$; Mucoromycota: $0.02 \%$; Figure S3B). Among the Ascomycota, Dothideomycetes ( $40 \%$ ) and Sordariomycetes (12\%) were the richest classes. However, while Dothideomycetes still presented the highest abundance (76\%), being followed by Leotiomycetes (7\%), Sordariomycetes displayed a reduced number of reads (1\%). The predominance of Ascomycota members within olive tissues has already been reported. The high abundance of Dothideomycetes and Sordariomycetes classes was previously described in the olive phyllosphere, carposphere, and rhizosphere, using metabarcoding approaches (Abdelfattah et al., 2015; Fernández-González et al., 2019). Also,
Leotiomycetes were described in the olive phyllosphere using culture-dependent methods (Materatski et al., 2019). From the top 25 most abundant families, about one third have never been described as olive tree endophytes in previous studies, using either culture-based and/or metagenomics approaches, such as Phaeosphaeriaceae (Parastagonospora avenae), Sporidiobolaceae (Rhodotorula sp.) and Phaffomycetaceae (Wickerhamomyces anomalus), many corresponding to yeast fungi. At species level, from the 20 most abundant OTUs, only 5 species/genera had been previously described as olive tree endophytes, including Neofabraea vagabunda, Pseudocercospora, Aureobasidium, Cladosporium, and Alternaria alternata (Abdelfattah et al., 2015; Martins et al., 2016; Preto et al., 2017; Gomes et al., 2018; Materatski et al., 2019; Giampetruzzi et al., 2020; Vergine et al., 2020). In addition, the identified Foliophoma fallens and Mycena OTUs belong to previously detected families (Coniothyriaceae and Tricholomataceae, respectively; Gomes et al., 2018). More than $50 \%$ of the total abundance comprised only five fungal species. From Dothideomycetes, Parastagonospora avenae, a plant pathogen associated with leaf spots and stem canker in cereals (Quaedvlieg et al., 2013), comprised $19 \%$ of identified reads, followed by a Pleosporales member (14\%), a Pseudocercospora sp. (12 $\%)$ and Foliophoma fallens ( $8 \%$ ). This later species has been associated with leaf spots in olive trees (Crous and Groenewald, 2017), also displaying antifungal activity (Crespo et al., 2020). The Leotiomycetes sequences were almost exclusively from the causal agent of olive leprosy, Neofabraea vagabunda (12\%).

Different fungal endophyte profiles were found for each olive cultivar (Fig. 2). Ascomycota was always the richest and most abundant phylum, followed by Basidiomycota. As detected for the entire endophytic community, the Dothideomycetes class was the richest and most abundant in all cultivars, being the Pleosporales order (comprising Parastagonospora and Foliophoma genera) the richest in all olive cultivars
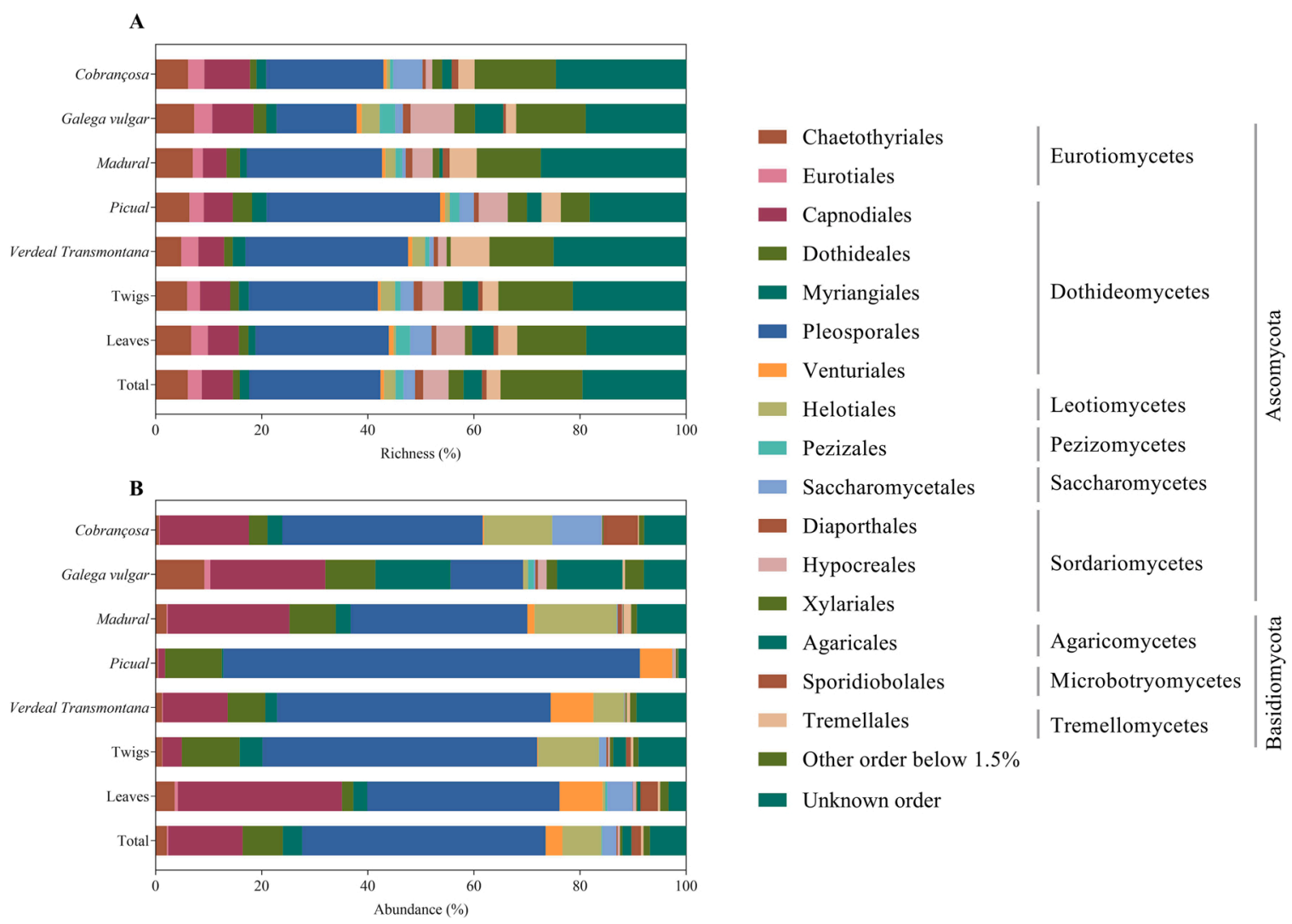

Fig. 2. Endophytic community structure of fungal orders in different olive tree cultivars and organs represented by richness (A) and abundance (B). Other orders comprise data with less than $1.5 \%$ of abundance/richness. Results for each cultivar are presented as the sum of organs for that cultivar, while for olive organ is the sum of all cultivars for each organ. 
(ranging from $33 \%$ to $15 \%$ ), followed by Capnodiales order (9\% to $4 \%$, mainly Pseudocercospora and Cladosporium genera). A different relative abundance profile for each cultivar was already reported for the phyllosphere fungal communities detected by cultural methods in different olive cultivars (Cobrançosa vs. Galega vulgar vs. Azeiteira, (Materatski et al., 2019); Cobrançosa vs. Verdeal Transmontana vs. Madural, Gomes et al., 2019), as well as for the root endosphere of 36 different cultivars from the World Olive Germoplasm Collection (Fernández-González et al., 2019). In the present work, while the most distinct community (cv. Picual) presented $78 \%$ of detected sequences belonging to Pleosporales, cv. Galega vulgar only presented $14 \%$ (comprising different Pleosporales spp.), but a higher relative abundance of Myriangiales (14 $\%)$ and Agaricales (12 \%). In any case, Pleosporales was one of the most abundant orders in all cultivars and Pleosporales OTUs (Parastagonospora avenae 7 and Foliophoma fallens) helped to explain the dissimilarity of cv. Picual to cvs. Cobrançosa and Galega vulgar (SIMPER results, Table S7). Also, Leotiomycetes (Dermateaceae family) only revealed a high abundance in some cultivars (mostly in cvs. Cobrançosa and Madural), which were all sampled in the same geographic location. Indeed, a Dermateaceae OTU (Neofabraea vagabunda) contributed for discriminating these cultivars from the others, explaining $2.8-5.1 \%$ of their dissimilarity (Table S7). Nearby olive tree orchards have been also described to display similar fungal endophytic communities (Martins et al., 2016).

Specific orders presented higher relative abundance in particular cultivars (Fig. 2). For example, Saccharomycetales were highly abundant in cv. Cobrançosa (9\%, mainly from Candida, Torulaspora, and Issatchenkia genera) and Helotiales in cv. Madural (15\%, mainly Neofabraea vagabunda). A Basidiomycota order (Agaricales; $12 \%$, mainly Mycena) was also highly abundant in cv. Galega vulgar. The best indicator taxa (IndVal > 0.6; Table S4) were Candida sp. 2 and Rhodotorula sp. for cv. Cobrançosa; Cladosporium sp. 2, Preussia sp. 5, Mycena sp. 1, as other unclassified OTUs for cv. Galega vulgar; Taphrina sp. for cv. Madural; Parastagonospora avenae 36 and Foliophoma fallens for cv. Picual. Indicator species to cv. Verdeal Transmontana were not identified to lower taxonomic classification than order (unknown Chaetothyriales 2).

All these results suggest a cultivar-specific fungal community, which is further noticed after analyzing the number of shared and exclusive OTUs (Fig. 3A). The cv. Galega vulgar had the highest number of exclusive OTUs (113), followed by cvs. Cobrançosa (65), Madural (53), Picual (41) and Verdeal Transmontana (40). Only 21 OTUs were shared among all cultivars (Table 2 and Table S4). This core olive community was mostly from Pleosporales order (7 OTUs) and Capnodiales order (2 OTUs) and included the previously reported olive endophytes Pseudocercospora, Aureobasidium and Cladosporium (Table S4). Indeed, these genera seem to be ubiquitous in olive tree, as they were identified in several other studies including other olive cultivars (Abdelfattah et al., 2015; Preto et al., 2017; Gomes et al., 2018; Materatski et al., 2019; Giampetruzzi et al., 2020; Vergine et al., 2020).

\subsection{Composition of fungal endophytic communities associated with olive twigs and leaves}

Among olive tree organs, the richness of fungal orders was very similar, also presenting Pleosporales, Chaetothyriales and Capnodiales as the richest orders $(24 \%-25 \%, 6 \%-8 \%$ and $6 \%-6 \%$ in twigs-leaves, respectively). However, twigs presented a higher relative abundance in Pleosporales (52 \%, compared with $36 \%$ detected in leaves, including Parastagonospora avenae and Foliophoma fallens genera), followed by Helotiales (11 \% compared with $0.5 \%$ in leaves). Indeed, Pseudocercospora sp. and Parastagonospora avenae 7 OTUs explained $12.8 \%$ of the dissimilarity found between organs (SIMPER, Table S7). In contrast, leaves revealed a higher relative abundance in Pleosporales (36\%), Capnodiales (31 \%, mainly Pseudocercospora), Saccharomycetales (4 \%, mostly from Candida, Torulaspora, Issatchenkia and Rhodotorula genera) compared with twigs $(1.3 \%)$. Interestingly, these highly abundant leaf endophytes revealed to be rather specific for each cultivar. Yeasts (Candida, Torulaspora, Issatchenkia, and Rhodotorula) were particularly found in cv. Cobrançosa. These results agree with IndVal analyses that revealed that Candida sp. 2 and Rhodotorula sp. were good indicator taxa for cv. Cobrançosa (IndVal of $0.500(p=0.025)$ and $0.478(p=0.023)$, respectively; Table $\mathrm{S} 4$ ).

Due to the higher richness found in twigs, a higher number of exclusive OTUs was observed in this organ (237, in comparison with the 90 exclusively found in leaves, Fig. 3B). From these, only 9 OTUs were found in all cultivar leaves and 16 in all cultivar twigs (Figure S4). Only 6 OTUs were found in both organs in all cultivars, including Cladosporium sp. 1, Aureobasidium sp., Alternaria alternata, unknown Dothideaceae, unknown Pleosporales 1, and unknown Pleosporales 11 (Table 2 and Table S4). Furthermore, from the detected olive core community (comprising the 21 OTUs), Parastagonospora avenae 7 and unknown Pleosporales 1 were found with high abundance in the twigs of all
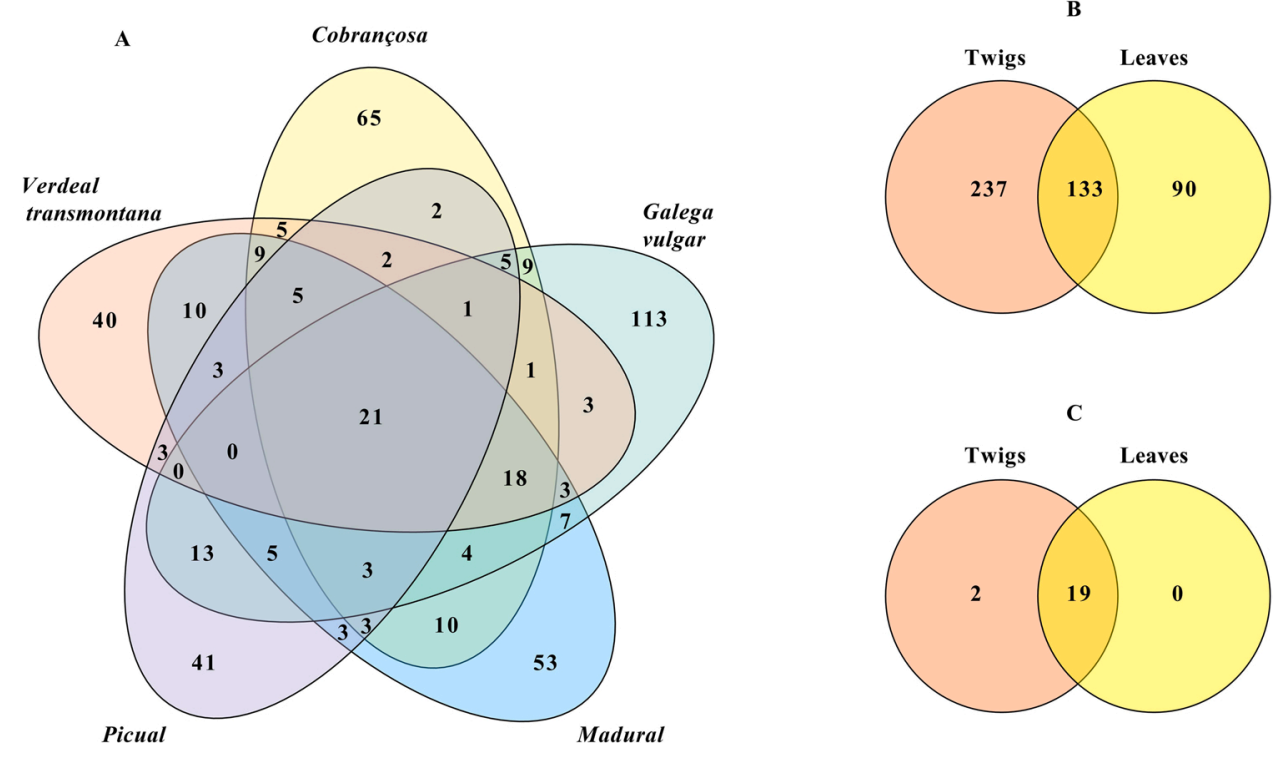

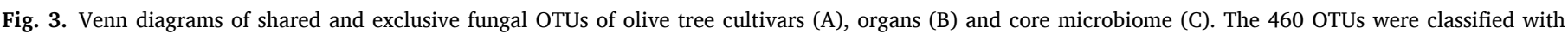

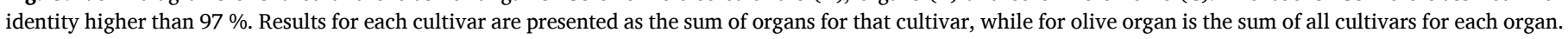


Table 2

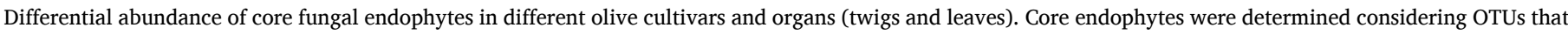
were present in all cultivars. Those OTUs present in all cultivars and organs (twigs and leaves) are depicted in bold.

\begin{tabular}{|c|c|c|c|c|c|c|c|c|c|c|}
\hline \multirow{2}{*}{ Taxonomy } & \multicolumn{5}{|l|}{ Twigs } & \multicolumn{5}{|c|}{ Leaves } \\
\hline & Cobr & Gal & Mad & Pic & Verd & Cobr & Gal & Mad & Pic & Verd \\
\hline \multicolumn{11}{|l|}{ Ascomycota } \\
\hline \multicolumn{11}{|l|}{$\overline{\text { Dothideomycetes }}$} \\
\hline \multicolumn{11}{|l|}{ Cladosporiaceae } \\
\hline Cladosporium sp. 1 & $* *$ & $*$ & $* *$ & $* *$ & $* *$ & * & $* *$ & * & * & $*$ \\
\hline \multicolumn{11}{|l|}{ Mycosphaerellaceae } \\
\hline Pseudocercospora sp. & & & $* *$ & & $* *$ & $* * * *$ & $* * *$ & $* * * *$ & * & $* * *$ \\
\hline \multicolumn{11}{|l|}{ Aureobasidiaceae } \\
\hline Aureobasidium sp. & $* *$ & $* *$ & $* *$ & $* * *$ & $*$ & & $* *$ & * & * & * \\
\hline \multicolumn{11}{|l|}{ Dothideaceae } \\
\hline \multicolumn{11}{|l|}{ Coniothyriaceae } \\
\hline Foliophoma fallens & * & $* *$ & * & $* * * *$ & $* *$ & * & & * & $* * * *$ & $* *$ \\
\hline \multicolumn{11}{|l|}{ Cucurbitariaceae } \\
\hline Unknown Cucurbitariaceae & & * & $* *$ & * & $*$ & * & & & * & * \\
\hline \multicolumn{11}{|l|}{ Didymosphaeriaceae } \\
\hline Paraconiothyrium sp. & * & * & & & * & & & & & \\
\hline \multicolumn{11}{|l|}{ Phaeosphaeriaceae } \\
\hline Parastagonospora avenae 7 & $* * *$ & * & $* *$ & $* * * *$ & $* * * *$ & $* * *$ & & $* *$ & $* *$ & $* * *$ \\
\hline \multicolumn{11}{|l|}{ Pleosporaceae } \\
\hline Alternaria alternata & * & * & * & $* *$ & * & * & * & * & * & * \\
\hline Unknown Pleosporales 1 & $* * * *$ & $* *$ & $* * *$ & $* *$ & $* * *$ & $* * *$ & $* *$ & $* * *$ & $* *$ & $* * *$ \\
\hline Unknown Pleosporales 11 & $*$ & $*$ & * & $* *$ & * & * & * & & * & $*$ \\
\hline Unknown Myriangiales 1 & $* *$ & $* * *$ & $* *$ & $*$ & $* *$ & * & $* *$ & $* *$ & & * \\
\hline Unknown Dothideomycetes 2 & $* *$ & * & * & * & $*$ & & & & & \\
\hline \multicolumn{11}{|l|}{ Eurotiomycetes } \\
\hline \multicolumn{11}{|l|}{ Herpotrichiellaceae } \\
\hline Capronia sp. 1 & * & & * & & & & $* *$ & * & & \\
\hline \multicolumn{11}{|l|}{ Lecanoromycetes } \\
\hline \multicolumn{11}{|l|}{ Stictidaceae } \\
\hline Schizoxylon albescens & * & & & * & * & & & & & \\
\hline \multicolumn{11}{|l|}{ Saccharomycetes } \\
\hline \multicolumn{11}{|l|}{ Saccharomycetaceae } \\
\hline Saccharomyces sp. & * & & & & & * & & * & & \\
\hline Unknown Ascomycota 1 & $* *$ & & * & & * & & & & & \\
\hline \multicolumn{11}{|l|}{ Basidiomycota } \\
\hline \multicolumn{11}{|l|}{ Malasseziomycetes } \\
\hline 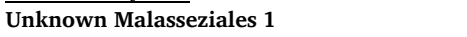 & & & * & & & & & & & \\
\hline Tremellomycetes & & & & & & & & & & \\
\hline Bulleribasidiaceae & & & & & & & & & & \\
\hline Vishniacozyma sp. 2 & * & * & * & & * & & & * & & \\
\hline Unknown Fungi & & & & & & & & & & \\
\hline Unknown Fungi 16 & * & & * & & $* *$ & & & * & & * \\
\hline Unknown Fungi 19 & * & $* *$ & $* *$ & * & $* *$ & & & * & & \\
\hline
\end{tabular}

*Represents more than $5, * *$ more than $50, * * *$ more than 500 and $* * * *$ more than 1500 sequences.

cultivars. Analysis of indicator species revealed that the indicator OTUs of twigs included some unclassified OTUs from Dothideomycetes, Neofabraea vagabunda (IndVal $=0.568, p=0.03$ ), Comoclathris spartii (IndVal $=0.527, p=0.02$ ), while Pseudocercospora sp. (IndVal $=0.809, p$ $=0.001$ ) was an indicator OTU for leaves. Also, the divergence of the fungal community found in the twigs of cv. Picual (from the twigs communities of cvs. Cobrançosa, Galega vulgar and Madural) was explained by several OTUs, including Parastagonospora avenae 7 and unknown Pleosporales 1, which explained $7.9 \%$ and $5.7 \%$ of their divergence, respectively, as detected by SIMPER analysis (Table S7). Furthermore, Neofabraea vagabunda was found in higher abundance in the cultivars collected in Bragança (Cobrançosa, Madural and Verdeal Transmontana). Indeed, Gomes et al. (2019) found the genus Neofabraea in the same cultivars by culture-dependent methods, although this genus was not the most abundant.

\subsection{The functional role of endophytic fungal community}

The olive tree is continuously challenged by diverse fungal pathogens that could compromise olive crop production. From the fungal species known as olive tree pathogens (Chliyeh et al., 2014), Verticillium dahliae, Venturia oleaginea, and Colletotrichum spp. are real threats to olive cultivation, as they are responsible for diseases like verticillium wilt, peacock spot and anthracnose, respectively. Except for Colletotrichum (only present in cv. Galega vulgar) we have not detected the other referred pathogens. However, from the most abundant OTUs, the pathogen Neofabraea vagabunda, known to cause olive leprosy or lepra fruit rot, branch cankers and dieback of twigs on olive tree (Romero et al., 2017) was detected in all cultivars (except on cv. Picual). Although in this work this pathogen was not detected in cv. Picual, this olive cultivar was the first to reveal symptoms of this disease in the Mediterranean Basin (Romero et al., 2015). The cv. Picual also presented a reduced abundance of Pseudocercospora sp., in contrast to the high abundance found in all other olive cultivars. P. cladosporioides have been recognized as the causal agent of a serious defoliating disease of olives, known as cercospora leaf spot (Ávila et al., 2005). As the sampled olive trees were apparently healthy, these results suggest that the presence of pathogens was not directly related to olive disease symptoms and other factors are needed for disease establishment.

When evaluating the ecological functions of detected fungal endophytes in studied olive cultivars, a different abundance profile was found for each olive cultivar (Fig. 4). Although cvs. Madural, Picual and Verdeal Transmontana revealed a high abundance of pathogenassociated OTUs, which included taxa with olive and non-olive disease 


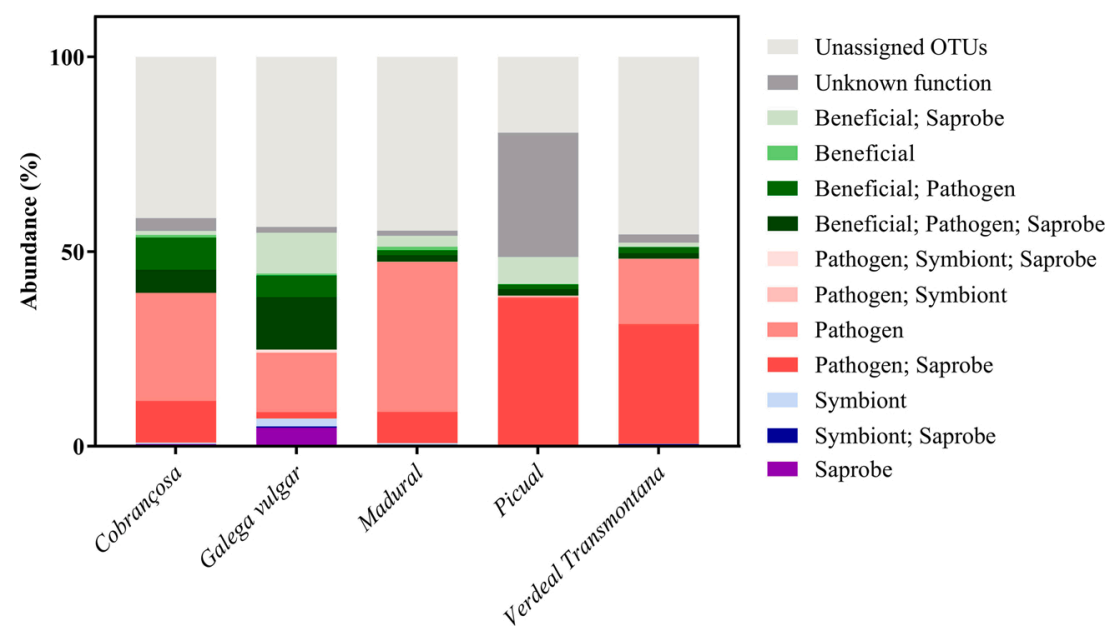

Fig. 4. Relative abundance of functional groups of fungal endophytes identified in olive tree cultivars. Results for each cultivar are presented as the sum of organs for that cultivar.

reports, cv. Cobrançosa and particularly cv. Galega vulgar presented a high rate of beneficial taxa. Such differences could, at least in part, influence their tolerance or susceptibility to certain diseases. Accordingly, cv. Picual has been described as susceptible to Verticillium wilt, while cv. Cobrançosa is described as tolerant (López-Escudero et al., 2004). However, despite the opposing ecological profile depicted by endophytes on cvs. Galega vulgar and Madural, they have been both described as susceptible to anthracnose (Gomes et al., 2009; Torres, 2007), while Cobrançosa, Picual and Verdeal Transmontana are referred as tolerant (Gomes et al., 2009; Moral and Trapero, 2009; Preto et al., 2017). Accordingly, cv. Cobrançosa revealed a high relative abundance of native yeasts (mainly Rhodotorula, Candida, Aureobasidium, Torulaspora, Issatchenkia, and Saccharomyces OTUs), some of which have already revealed a potential antifungal activity against the causal agent of anthracnose (namely, Candida spp., Pesce et al., 2018; Saccharomyces sp., Lopes et al., 2015 and Aureobasidium sp., Nigro et al., 2018). However, the colonization of plant tissues/organs by a single microorganism (pathogen or beneficial) does not render higher or reduced susceptibility of a plant to a certain disease. Recent reports suggest that the establishment and progression of plant diseases is determined by the wide diversity of microbial taxa inhabiting plant tissues (either pathogenic, beneficial or neutral) as well as by the interactions among them and plant host (Bettenfeld et al., 2020). The contribution of olive genotype (at cultivar level) for the assembling of olive-associated microbiota was recently described to be related to increased or reduced susceptibility to olive diseases (Gomes et al., 2019; Giampetruzzi et al., 2020; Mina et al., 2020b; Vergine et al., 2020). Accordingly, modifications in the microbial networks in the presence of a pathogen have been associated with higher susceptibility/tolerance to olive diseases, such as verticillium wilt (Fernández-González et al., 2020), anthracnose (Preto et al., 2017), olive quick decline syndrome (Vergine et al., 2020) or olive knot caused by Pseudomomas savastanoi pv. savastanoi (Gomes et al., 2019; Mina et al., 2020a).

\section{Conclusions}

The description of whole microbiota in different olive cultivars can open new opportunities for understanding the microbial interactions that lead to olive disease establishment/progression. In this work, the fungal endophytes inhabiting the phyllosphere (leaf and twigs) of different olive cultivars were revealed. Besides the already described common endophytes present in these tissues, as detected by culture dependent approaches, a deeper insight was made by using a metabarcoding approach. Using this methodology, a still hardly studied fungal community, such as yeasts, was uncovered. However, there is still a large amount of fungal diversity to be discovered, due to the large amount of unclassified OTUs detected. Previous identified olive endophytes were likewise recognized in this work as components of the core olive tree microbiota, including Pseudocercospora sp., Aureobasidium sp., Cladosporium sp., and Alternaria alternata, but others were similarly recognized in all cultivars (for example, Parastagonospora avenae, Foliophoma fallens, as well as Vishniacozyma sp. and Saccharomyces sp. yeasts, among others).

Different endophyte communities were detected in distinct olive cultivars, in agreement with the already reported role of genotype (at cultivar level) on the assembling of microbial communities. The cv. Galega vulgar exhibited the most diverse fungal community, contrasting with cv. Picual, which depicted the most divergent endophyte community from the other cultivars. However, a different trend was observed for each olive organ. While leaf communities of different cultivars were highly homogenous, twig endophyte communities were more divergent among distinct cultivars. This result could be related with the physical features of twigs that are more prone to retain microbial communities than leaves, whose fungal communities are more exposed to environmental conditions. The particular fungal composition exhibited by each olive cultivar could play a role on the facilitation of specific disease progression. For example, cv. Cobrançosa was singled out by displaying a highly abundant yeast community (mainly on leaves), some members of which have already been recognized as biocontrol agents against anthracnose. Different cultivars also exhibited dissimilar amounts of fungi with distinct ecological functions, which could explain their differential susceptibilities/tolerances to olive diseases.

\section{Funding}

This work was supported by FEDER funds through COMPETE (Programa Operacional Factores de Competitividade) and by national funds by FCT (Fundação para a Ciência e a Tecnologia) in the framework of the projects EXCL/AGR-PRO/0591/2012, PTDC/AGR-PRO/4354/2012, and PTDC/ASP-PLA/31133/2017, as well as BioISI (UIDB/04046/2020) and Mountain Research Center - CIMO (UIDB/00690/2020).

\section{Author statement}

The authors declare that the reported work is original, all authors have seen and approved the submitted version of the manuscript, and all prevailing local, national and international regulations and conventions, and normal scientific ethical practices, have been respected. None of the material has been published or is under consideration elsewhere. 


\section{Declaration of Competing Interest}

The authors report no declarations of interest.

\section{Appendix A. Supplementary data}

Supplementary material related to this article can be found, in the online version, at doi:https://doi.org/10.1016/j.micres.2020.126693.

\section{References}

Abdelfattah, A., Li Destri Nicosia, M.G., Cacciola, S.O., Droby, S., Schena, L., 2015 Metabarcoding analysis of fungal diversity in the phyllosphere and carposphere of olive (Olea europaea). PLoS One 10, e0131069. https://doi.org/10.1371/journal. pone.0131069.

Aktar, W., Sengupta, D., Chowdhury, A., 2009. Impact of pesticides use in agriculture: their benefits and hazards. Interdiscip. Toxicol. 2, 1-12. https://doi.org/10.2478/ v10102-009-0001-7.

Albanese, D., Fontana, P., De Filippo, C., Cavalieri, D., Donati, C., 2015. MICCA: a complete and accurate software for taxonomic profiling of metagenomic data. Sci. Rep. 5, 9743. https://doi.org/10.1038/srep09743.

Anguita-Maeso, M., Olivares-García, C., Haro, C., Imperial, J., Navas-Cortés, J.A., Landa, B.B., 2020. Culture-dependent and culture-independent characterization of the olive xylem microbiota: effect of sap extraction methods. Front. Plant Sci. 10, 1708. https://doi.org/10.3389/fpls.2019.01708.

Aranda, S., Montes-Borrego, M., Jiménez-Díaz, R.M., Landa, B.B., 2011. Microbial communities associated with the root system of wild olives (Olea europaeaL. subsp. europaea var. sylvestris) are good reservoirs of bacteria with antagonistic potential against Verticillium dahliae. Plant Soil 343, 329-345. https://doi.org/10.1007/ s11104-011-0721-2.

Aronesty, E., 2011. ea-utils: Command-line tools for processing biological sequencing data. Durham, NC.

Ávila, A., Groenewald, J., Trapero, A., Crous, P.W., 2005. Characterisation and epitypification of Pseudocercospora cladosporioides, the causal organism of Cercospora leaf spot of olives. Mycol. Res. 109, 881-888. https://doi.org/10.1017/ s0953756205003503.

Azabou, M.C., Gharbi, Y., Medhioub, I., Ennouri, K., Barham, H., Tounsi, S., Triki, M.A., 2020. The endophytic strain Bacillus velezensis OEE1: an efficient biocontrol agent against Verticillium wilt of olive and a potential plant growth promoting bacteria Biol. Control 142, 104168. https://doi.org/10.1016/j.biocontrol.2019.104168.

Backman, P.A., Sikora, R.A., 2008. Endophytes: an emerging tool for biological control Biol. Control 46, 1-3. https://doi.org/10.1016/j.biocontrol.2008.03.009.

Bettenfeld, P., Fontaine, F., Trouvelot, S., Fernandez, O., Courty, P.E., 2020. Woody plant declines. What's wrong with the microbiome? Trends Plant Sci. 25, 381-394. https://doi.org/10.1016/j.tplants.2019.12.024.

Caporaso, J.G., Kuczynski, J., Stombaugh, J., Bittinger, K., Bushman, F.D., Costello, E.K., Fierer, N., Peña, A.G., Goodrich, J.K., Gordon, J.I., Huttley, G.A., Kelley, S.T., Knights, D., Koenig, J.E., Ley, R.E., Lozupone, C.A., McDonald, D., Muegge, B.D., Pirrung, M., Reeder, J., Sevinsky, J.R., Turnbaugh, P.J., Walters, W.A., Widmann, J., Yatsunenko, T., Zaneveld, J., Knight, R., 2010. QIIME allows analysis of highthroughput community sequencing data. Nat. Methods 7, 335. https://doi.org/ 10.1038/nmeth.f.303.

Cardinale, M., Luvisi, A., Meyer, J.B., Sabella, E., De Bellis, L., Cruz, A.C., Ampatzidis, Y, Cherubini, P., 2018. Specific fluorescence in situ hybridization (FISH) test to highlight colonization of xylem vessels by Xylella fastidiosa in naturally infected olive trees (Olea europaea L.). Front. Plan Sci. 9, 431. https://doi.org/10.3389/ fpls.2018.00431.

Cariddi, C., Saponari, M., Boscia, D., De Stradis, A., Loconsole, G., Nigro, F., Porcelli, F., Potere, O., Martelli, G.P., 2014. Isolation of a Xylella fastidiosa strain infecting olive and oleander in Apulia, Italy. Plant Pathol. J. 96, 425-429.

Chliyeh, M., Touati, J., Selmaoui, K., Touhami, A.O., Filali-Maltouf, A., El Modafar, C., Douira, A., 2014. Bibliographic inventory of the olive tree (Olea europaea L.) fungal diseases in the world. Int. J. Pure. Appl. Biosci. 2, 46-79.

Clarke, K.R., 1993. Non-parametric multivariate analyses of changes in community structure. Aust. J. Ecol. 18, 117-143. https://doi.org/10.1111/j.1442-9993.1993. tb00438.x.

Compant, S., Samad, A., Faist, H., Sessitsch, A., 2019. A review on the plant microbiome: ecology, functions and emerging trends in microbial application. J. Adv. Res. 19, 29-37. https://doi.org/10.1016/j.jare.2019.03.004.

Copeland, J.K., Yuan, L., Layeghifard, M., Wang, P., Guttman, D.S., 2015. Seasonal community succession of the phyllosphere microbiome. Mol. Plant. Microbe. Interac. 28, 274-285. https://doi.org/10.1094/MPMI-10-14-0331-FI.

Crespo, G., Pérez-Victoria, I., Ortiz-López, F.J., González-Menéndez, V., de la Cruz, M., Cautain, B., Sánchez, P., Vicente, F., Genilloud, O., Reyes, F., 2020. Structural elucidation of antibiotic TKR2999, an antifungal lipodepsipeptide isolated from the fungus Foliophoma fallens. Antibiotics Basel (Basel) 9, 278. https://doi.org/10.3390/ antibiotics 9060278 .

Crous, P.W., Groenewald, J.Z., 2017. The genera of fungi-G 4: Camarosporium and Dothiora. IMA Fungus 8, 131-152. https://doi.org/10.5598/ imafungus. 2017.08.01.10.

de Freitas Sia, E., Marcon, J., Luvizotto, D.M., Quecine, M.C., Tsui, S., Pereira, J.O., Pizzirani-Kleiner, A.A., Azevedo, J.L., 2013. Endophytic fungi from the Amazonian plant Paullinia cupana and from Olea europaea isolated using cassava as an alternative starch media source. SpringerPlus. 2, 579. https://doi.org/10.1186/ 2193-1801-2-579.

de Lamo, F.J., Takken, F.L., 2020. Biocontrol by Fusarium oxysporum using endophytemediated resistance. Front. Plant Sci. 11, 37. https://doi.org/10.3389/ fpls.2020.00037.

de Silva, N.I., Brooks, S., Lumyong, S., Hyde, K.D., 2019. Use of endophytes as biocontrol agents. Fungal Biol. Rev. 33, 133-148. https://doi.org/10.1016/j.fbr.2018.10.001.

Delrio, G., Lentini, A., 2017. Pest management in organic olive. In: Vacante, V., Kreiter, S. (Eds.), Handbook of Pest Management in Organic Farming. CABI, Boston, MA, pp. 218-231.

Dufrene, M., Legendre, P., 1997. Species assemblages and indicator species: the need for a flexible asymmetrical approach. Ecol. Monogr. 67, 345-366. https://doi.org/ 10.1890/0012-9615(1997)067[0345:SAAIST]2.0.CO;2.

Edgar, R., 2010. Search and clustering orders of magnitude faster than BLAST. Bioinformatics. 26, 2460-2461. https://doi.org/10.1093/bioinformatics/btq461.

Eljounaidi, K., Lee, S.K., Bae, H., 2016. Bacterial endophytes as potential biocontrol agents of vascular wilt diseases-review and future prospects. Biol. Control 103, 62-68. https://doi.org/10.1016/j.biocontrol.2016.07.013.

Fernández-González, A.J., Villadas, P.J., Cabanás, C.G.L., Valverde-Corredor, A., Belaj, A., Mercado-Blanco, J., Fernández-López, M., 2019. Defining the root endosphere and rhizosphere microbiomes from the World Olive Germplasm Collection. Sci. Rep. 9, 1-13. https://doi.org/10.1038/s41598-019-56977-9.

Fernández-González, A.J., Cardoni, M., Cabanás, C.G.L., Valverde-Corredor, A., Villadas, P.J., Fernández-López, M., Mercado-Blanco, J., 2020. Linking belowground microbial network changes to different tolerance level towards Verticillium wilt of olive. Microbiome 8, 11. https://doi.org/10.1186/s40168-020-0787-2.

Giampetruzzi, A., Baptista, P., Morelli, M., Cameirão, C., Lino Neto, T., Costa, D., D’Attoma, G., Abou Kubaa, R., Altamura, G., Saponari, M., Pereira, J.A., 2020. Differences in the endophytic microbiome of olive cultivars infected by Xylella fastidiosa across seasons. Pathogens 9, 723. https://doi.org/10.3390/ pathogens 9090723.

Gomes, S., Prieto, P., Martins-Lopes, P., Carvalho, T., Martin, A., Guedes-Pinto, H., 2009. Development of Colletotrichum acutatum on tolerant and susceptible Olea europaea L. cultivars: a microscopic analysis. Mycopathologia 168, 203-211. https://doi.org/ 10.1007/s11046-009-9211-y.

Gomes, T., Pereira, J.A., Benhadi, J., Lino-Neto, T., Baptista, P., 2018. Endophytic and epiphytic phyllosphere fungal communities are shaped by different environmental factors in a Mediterranean ecosystem. Microb. Ecol. 76, 668-679. https://doi.org/ 10.1007/s00248-018-1161-9.

Gomes, T., Pereira, J.A., Lino-Neto, T., Bennett, A.E., Baptista, P., 2019. Bacterial disease induced changes in fungal communities of olive tree twigs depend on host genotype. Sci. Rep. 9, 5882. https://doi.org/10.1038/s41598-019-42391-8.

Good, I.J., 1953. The population frequencies of species and the estimation of population parameters. Biometrika 40, 237-264.

Hammer, Ø., Harper, D.A.T., Ryan, P.D., 2001. PAST: paleontological statistics software package for education and data analysis. Palaeontol. Electron. 4, 9. http://palaeo-el ectronica.org/2001_1/past/issue1_01.htm.

Hardoim, P.R., Van Overbeek, L.S., Berg, G., Pirttilä, A.M., Compant, S., Campisano, A., Döring, M., Sessitsch, A., 2015. The hidden world within plants: ecological and evolutionary considerations for defining functioning of microbial endophytes. Microbiol. Mol. Biol. Rev. 79, 293-320. https://doi.org/10.1128/MMBR.00050-14.

Henderson, P.A., Seaby, R.M.H., 2014. Community Analysis Package Version 5. Pisces Conservation Ltd, Lymington, UK.

Hill, T.C., Walsh, K.A., Harris, J.A., Moffett, B.F., 2003. Using ecological diversity measures with bacterial communities. FEMS Microbiol. Ecol. 43, 1-11. https://doi. org/10.1111/j.1574-6941.2003.tb01040.x.

Hughes, J.B., Bohannan, B.J.M., 2004. Application of ecological diversity statistics in microbial ecology. Molecular Microbial Ecology Manual, 2nd edition. Kluwer Academic Publishers, Dordrecht, the Netherlands.

Joshi, N.A., Fass, J.N., 2011. Sickle: a Sliding-window, Adaptive, Quality-based Trimming Tool for FastQ Files (version 1.33).

Kruskal, J.B., Wish, M., 1978. Multidimensional Scaling, 11th ed. Sage.

Lopes, M.R., Klein, M.N., Ferraz, L.P., da Silva, A.C., Kupper, K.C., 2015. Saccharomyces cerevisiae: a novel and efficient biological control agent for Colletotrichum acutatum during pre-harvest. Microbiol. Res. 175, 93-99. https://doi.org/10.1016/j. micres.2015.04.003.

López-Escudero, F.J., Del Rio, C., Caballero, J.M., Blanco-López, M.A., 2004. Evaluation of olive cultivars for resistance to Verticillium dahliae. Eur. J. Plant Pathol. 110, 79-85. https://doi.org/10.1023/B:EJPP.0000010150.08098.2d.

Magurran, A.E., 1988. Ecological Diversity and Its Measurement. Springer Science \& Business Media. https://doi.org/10.1007/978-94-015-7358-0.

Malavolta, C., Perdikis, D., 2018. Crop specific technical guidelines for integrated production of olives. IOBC-WPRS Commission IP Guidelines, 4th edition, pp. 1-19. 77.

Martins, F., Pereira, J.A., Bota, P., Bento, A., Baptista, P., 2016. Fungal endophyte communities in above-and belowground olive tree organs and the effect of season and geographic location on their structures. Fungal Ecol. 20, 193-201. https://doi. org/10.1016/j.funeco.2016.01.005.

Materatski, P., Varanda, C., Carvalho, T., Dias, A.B., Campos, M.D., Rei, F., do Rosário Félix, M., 2019. Spatial and temporal variation of fungal endophytic richness and diversity associated to the phyllosphere of olive cultivars. Fungal Biol. 123, 66-76. https://doi.org/10.1016/j.funbio.2018.11.004.

Mina, D., Pereira, J.A., Lino-Neto, T., Baptista, P., 2020a. Impact of plant genotype and plant habitat in shaping bacterial pathobiome: a comparative study in olive tree. Sci. Rep. 10, 1-11. https://doi.org/10.1038/s41598-020-60596-0. 
Mina, D., Pereira, J.A., Lino-Neto, T., Baptista, P., 2020b. Epiphytic and endophytic bacteria on olive tree phyllosphere: exploring tissue and cultivar effect. Microb. Ecol. https://doi.org/10.1007/s00248-020-01488-8.

Mitchell, J.I., Zuccaro, A., 2006. Sequences, the environment and fungi. Mycologist 20, 62-74. https://doi.org/10.1016/j.mycol.2005.11.004.

Moral, J., Trapero, A., 2009. Assessing the susceptibility of olive cultivars to anthracnose caused by Colletotrichum acutatum. Plant Dis. 93, 1028-1036. https://doi.org/ 10.1094/PDIS-93-10-1028.

Müller, H., Berg, C., Landa, B.B., Auerbach, A., Moissl-Eichinger, C., Berg, G., 2015. Plant genotype-specific archaeal and bacterial endophytes but similar Bacillus antagonists colonize Mediterranean olive trees. Front. Microbiol. 6, 138. https://doi.org/ 10.3389/fmicb.2015.00138.

Nguyen, N.H., Song, Z., Bates, S.T., Branco, S., Tedersoo, L., Menke, J., Schilling, J.S., Kennedy, P.G., 2016. FUNGuild: an open annotation tool for parsing fungal community datasets by ecological guild. Fungal Ecol. 20, 241-248. https://doi.org/ 10.1016/j.funeco.2015.06.006.

Nigro, F., Antelmi, I., Labarile, R., Sion, V., Pentimone, I., 2018. Biological control of olive anthracnose. Acta Hortic. https://doi.org/10.17660/ActaHortic.2018.1199.70.

Nilsson, R.H., Larsson, K.-H., Taylor, A.F.S., Bengtsson-Palme, J., Jeppesen, T.S., Schigel, D., Kennedy, P., Picard, K., Glöckner, F.O., Tedersoo, L., Saar, I., Kõljalg, U., Abarenkov, K., 2018. The UNITE database for molecular identification of fungi: handling dark taxa and parallel taxonomic classifications. Nucleic Acids Res. https:// doi.org/10.1093/nar/gky1022.

Nurk, S., Bankevich, A., Antipov, D., Gurevich, A., Korobeynikov, A., Lapidus, A., Prjibelsky, A., Pyshkin, A., Sirotkin, A., Sirotkin, Y., Stepanauskas, R., McLean, J., Lasken, R., Clingenpeel, S.R., Woyke, T., Tesler, G., Alekseyev, M.A., Pevzner, P.A., 2013. Assembling genomes and mini-metagenomes from highly chimeric reads, $p$ 158-170. In: Deng, M., Jiang, R., Sun, F., Zhang, X. (Eds.), Research in Computational Molecular Biology. Springer, Berlin, Heidelberg. https://doi.org/ 10.1007/978-3-642-37195-0_13.

Oksanen, J., Blanchet, F.G., Friendly, M., Kindt, R., Legendre, P., McGlinn, D., Minchin, P.R., O'Hara, R.B., Simpson, G.L., Solymos, P., Henry, M., Stevens, H., Szoecs, E., Wagner, H., 2019. Vegan: Community Ecology Package (R Package Version 2.5-4). https://CRAN.R-project.org/package=vegan.

Pascazio, S., Crecchio, C., Ricciuti, P., Palese, A.M., Xiloyannis, C., Sofo, A., 2015. Phyllosphere and carposphere bacterial communities in olive plants subjected to different cultural practices. Int. J. Plant. Biol. 6 https://doi.org/10.4081/ pb.2015.6011.
Pesce, V.M., Nally, M.C., Carrizo, G.P., Rojo, C., Pérez, B.A., Toro, M.E., Castellanos de Figueroa, L.I., Vazquez, F., 2018. Antifungal activity of native yeasts from different microenvironments against Colletotrichum gloeosporioides on ripe olive fruits. Biol. Control 120, 43-51. https://doi.org/10.1016/j.biocontrol.2017.03.005.

Pingali, P.L., Gerpacio, R.V., 1997. Towards Reduced Pesticide Use for Cereal Crops in Asia. CIMMYT Economics Working Paper 97-04. CIMMYT, Mexico, D.F.

Preto, G., Martins, F., Pereira, J.A., Baptista, P., 2017. Fungal community in olive fruits of cultivars with different susceptibilities to anthracnose and selection of isolates to be used as biocontrol agents. Biol. Control 110, 1-9. https://doi.org/10.1016/j. biocontrol.2017.03.011.

Quaedvlieg, W., Verkley, G.J.M., Shin, H.D., Barreto, R.W., Alfenas, A.C., Swart, W.J., Groenewald, J.Z., Crous, P.W., 2013. Sizing up septoria. Stud. Mycol. 75, 307-390. https://doi.org/10.3114/sim0017.

Raymaekers, K., Ponet, L., Holtappels, D., Berckmans, B., Cammue, B.P., 2020. Screening for novel biocontrol agents applicable in plant disease management - A review. Biol. Control 144, 104240. https://doi.org/10.1016/j.biocontrol.2020.104240.

Romero, J., Raya, M.C., Roca, L.F., Moral, J., Trapero, A., 2015. First report of Neofabraea vagabunda causing branch cankers on olives in Spain. Plant Dis. 100 https://doi.org/10.1094/PDIS-06-15-0657-PDN, 527-527.

Romero, J., Raya, M.C., Roca, L.F., Agustí-Brisach, C., Moral, J., Trapero, A., 2017. Phenotypic, molecular and pathogenic characterization of Phlyctema vagabunda, causal agent of olive leprosy. Plant Pathol. 67, 277-294. https://doi.org/10.1111/ ppa.12748.

Smith, D.P., Peay, K.G., 2014. Sequence depth, not PCR replication, improves ecological inference from next generation DNA sequencing. PLoS One 9, e90234. https://doi. org/10.1371/journal.pone.0090234.

Torres, L., 2007. A protecção integrada do olival no contexto da produção integrada. In: Torres, L., Azevedo, J. (Eds.), Manual de protecção integrada do olival. Mirandela, Portugal.

Uylaşer, V., Yildiz, G., 2014. The historical development and nutritional importance of olive and olive oil constituted an important part of the Mediterranean diet. Crit. Rev. Food Sci. Nutr. 54, 1092-1101. https://doi.org/10.1080/10408398.2011.626874.

Vergine, M., Meyer, J.B., Cardinale, M., Sabella, E., Hartmann, M., Cherubini, P., de Bellis, L., Luvisi, A., 2020. The Xylella fastidiosa-resistant olive cultivar "Leccino" has stable endophytic microbiota during the Olive Quick Decline Syndrome (OQDS). Pathogens. 9, 35. https://doi.org/10.3390/pathogens9010035. 